\title{
Gender representations in associative meaning: The image of woman in Russian and Yakut language consciousnesses
}

\author{
Sargylana Filippova ${ }^{1, *}$, Varvara Filippova ${ }^{2}$, Karina Pokoyakova $^{3}$, Varvara Filippova ${ }^{4}$, and Aureliia Khikhlun $^{5}$ \\ ${ }^{1}$ North-Eastern Federal University named after M.K. Ammosov, 677000 Yakutsk, Russian Federation \\ ${ }^{2}$ Academy of Sciences of the Republic of Sakha (Yakutia), 677007 Yakutsk, Russian Federation \\ ${ }^{3}$ Katanov Khakass State University, 655017 Abakan, Russian Federation \\ ${ }^{4}$ Arctic State Institute of Culture and Arts, 677000 Yakutsk, Russian Federation \\ ${ }^{5}$ Arctic State Agrotechnological University, 677007 Yakutsk, Russian Federation
}

\begin{abstract}
The study is focused on representations of the concept 'woman' existing in the language consciousnesses of representatives of the Russian and Yakut ethnic groups. The image of 'woman' was investigated by means of a free-associative experiment. The associative field, collected in the course of the experiment, is considered as the verbalization of language consciousness that reflects the image of the world, mediated by language. To identify the effect of the social environment as well as the role of native language in the preservation of traditional worldview elements, the associative experiment was conducted among Russians, Urban Yakuts (for whom Russian was the main or only language), and Rural Yakuts (who speak Yakut). The conclusions of our research are the following: the components of the associative meanings of the three experimental groups overlap due to commonalities in traditions and gender stereotypes existing in Russian and Yakut cultures. However, some responses of Rural Yakuts were specific for that group, showing that they preserved some elements of traditional perceptions of 'woman' in comparison with Urban Yakuts. Thus, we think that the usage of the ancestral language and the rural way of life contribute to the preservation and retention of traditional worldview elements.
\end{abstract}

\section{Introduction}

The images of consciousnesses of different ethnic groups are interesting objects of investigation and our work, which focused on images of language consciousnesses of members of the Yakut ethnic groups, is no exception. The objective of our study was to distinguish common and distinct features in the perception of the word 'woman' by Russian and Yakut respondents. We also attempted to compare the strategies of association produced by Urban and Rural Yakuts, socialized in different cultural and social contexts. The division of Yakut respondents into two groups can be explained by the fact that in the Russian Federation minority ethnic groups have been experiencing the impact of the predominant Russian language and culture [1-3]. Globalization processes are also contributing to the transformation of their mentality and way of life. The urban environment leads to the assimilation of minority ethnicities with majority ones and such 'unifying' processes result in the modification of the character of social connections, behavior, beliefs and worldview. In this context, we think that rural areas, where most activities are separated into male and female spheres, are more stable $[4,5]$. Rural areas are "highly gendered spaces" where "all the behaviors and actions reflect attitudes, beliefs, and opinions concerning the status, role, and responsibility of both sexes" [6]. Our previous studies revealed that those who are socialized in rural territories traditionally inhabited by the Yakuts preserved some elements of the traditional worldview that Urban Yakuts had lost (especially in the religious sphere) [7]. On the other hand, we found that in spite of globalization and the unification of cultures in the Russian Federation, gender stereotypes are the most stable representations; all three groups of subjects demonstrated highly 'gendered' strategies of association, indicating qualities, spheres and attributes characteristic of traditional perceptions of 'woman'.

The existence of gender stereotypes can be explained by the fact that "gender roles are formed through the socialization process" [8]. Scholars in the field of gender studies state that representations remain stable and stereotypic because gender roles are defined within the social environment $[9,10]$ under the pressure of traditions, religious beliefs, and economic and political factors. Gender roles are attributed "according to a society's beliefs about differences between the sexes" [11], meaning that gender stereotypes are based on biological and labor differentiation, 'norms' and 'standards' of behavior, traditional values transferred to younger generation by their elder relatives, etc. [12, 13].

In Russia, there is a high level of gender inequality that is verbalized in patriarchal stereotypes about certain models and norms of men's and women's behaviors, and strict labor differentiation based on sex $[14,15]$. The

\footnotetext{
Corresponding author: filippova_sargylana@mail.ru
} 
results of our study also confirmed the existence of patriarchal attitude towards 'woman' among all the groups of respondents as all the associative fields contained reactions verbalizing stereotypic representations of women's social role and qualities.

To reveal the effect of social environment on the preservation of elements of the traditional worldview, we conducted a study of the associative fields 'woman' / 'zhenshhina' / Jaxtar' among ethnic Russians, Urban Yakuts (for whom Russian was the main or only language), and Rural (Yakut-speaking) Yakuts. The inclusion of Russian respondents was important as their associative field served as the control material for determining correlates in the contents of Urban and Rural Yakuts' associative fields. Commonalities and differences in responses of the Yakuts socialized in different environments allowed us to investigate whether language shift (from Yakut to Russian) and an urban way of life result in shifts in the contents of images of consciousness. Overall, associative fields are convenient materials for study as their contents clearly demonstrate patriarchal and traditional components existing in the images and concepts of language consciousnesses. We hope that the materials from this study will be helpful to scholars conducting intercultural research on associative norms gathered from representatives of different ethnic groups.

\section{Methods}

Associative data are widely investigated in cross-cultural and gender research [16-22] as they amply illustrate common and divergent components existing in the images of language consciousnesses of different ethnic or gender groups.

Our associative experiment was conducted among students from colleges and universities in Yakutsk (Republic of Sakha (Yakutia). The respondents were 1621 years old and comprised three groups: Urban Yakuts, Rural Yakuts and Russians. We labelled the group of Yakuts who reported Russian as their main or only language of communication as 'Urban' as respondents were mainly from cities of Sakha Republic and industrial Russian-speaking areas. Those who reported Yakut as their main means of communication were mainly villagers, thus we labeled them 'Rural'. All of the Russian subjects reported Russian as their only language of communication, and none of them knew Yakut. The presence of the last experimental group allowed us to identify the common and divergent representations of Russian and Yakut respondents as well as the shifts in perception of the image of 'woman' by Urban Yakuts compared to Rural ones. Each group contained approximately 230-240 informants with approximately equal numbers of males and females.

To reveal commonalities and specificities in the contents of the image 'woman' in the language consciousnesses of the Russians, Urban and Rural
Yakuts, we used qualitative and quantitative methods of data analysis. The stages of the study were the following. (1) We singled out frequent answers from the associative fields of the stimulus words 'zhenshhina' / 'Jaxtar' ('woman'). (2) We analyzed and compared the components of associative fields and identified the correlations of frequent responses common to all the groups with those specific to one or more groups. (3) We divided frequent verbal reactions to the stimulus words into thematic groups. (4) We interpreted the presence of correlations and group-specific responses of the investigated subjects. Thus, at different stages of the study we applied the methods of quantitative, comparative, semantic, and interpretational analyses.

\section{Results}

For consistency and coherence in the description of the investigated groups, we use the abbreviations RAF (Russian Associative Field), UYAF (Urban Yakut Associative Field) and RYAF (Rural Yakut Associative Field). For convenience of presentation of the associative data, we marked verbal reactions in italics followed by the number of tokens of each response in parentheses or next to the reactions.

For all the groups of subjects, the stimulus 'woman' was associated, first of all, with the word man, and this opposition is the most frequent in RAF (55), followed by UYAF (45), and RYAF (33). As for Rural Yakuts, they also gave the frequent reaction mother (33) with the same quantitative indicators as man. The percentages of frequent responses (i.e., responses that occurred across groups) were as follows: $79.4 \%$ of RAF responses contained frequent answers, $74.5 \%$ of UYAF, and $82.5 \%$ of RYAF. The remaining responses were singlefrequency reactions.

It is important to point out that in the process of comparative analysis we faced some difficulties explained by the phenomenon of 'conversion' in the Yakut language. That is why the verbal reactions beautiful and beauty (adjectives and nouns in Russian) were grouped into one line, as all of them correlated with one Yakut conversional word keré. In all fields, there are correlations that demonstrate overlaps in the representation of 'woman', but most of the similarities are observed in RAF and UYAF (Table 1). The RYAF also contains the same responses, but the frequency of responses beautiful and girl differ from both RAF and UYAF. We observe that the link 'woman' - beautiful and beauty is stronger in RAF and UYAF. The reaction man is the most frequent in all the fields; it means that the associative link 'woman' - man based on the contrasting of gender is strong among all the groups of respondents. But it is necessary to note that in RYAF there are other frequent verbal reactions representing the strength of the links that reflect the close connection of 'woman' with maternity (mother / ije) and the importance of opposition based on age ( girl / kyys). 
Table 1. Correlation of frequencies.

\begin{tabular}{|l|l|l|l|}
\hline Meaning & RAF & UYAF & RYAF \\
\hline man & muzhchina 55 & muzhchina 45, muzhik 5 & ér kihi 33 \\
\hline mother & mat'30, mama 8 & mat' 24, mama 13 & ije 33 \\
\hline beautiful / beauty & $\begin{array}{l}\text { krasivaja 19, krasota 12, } \\
\text { krasavica 2 }\end{array}$ & $\begin{array}{l}\text { krasota 22, krasivaja 6, } \\
\text { krasivo 2 }\end{array}$ & kére 7, kyrahyabaj 3 \\
\hline wife & zhena 10 & zhena 6 & ojox 5 \\
\hline human & chelovek 8 & chelovek 4 & kihi 7 \\
\hline child & rebenok 5 & rebenok 7 & ogho 4 \\
\hline love & ljubov' 5 & ljubov' 2 & kyys 31 \\
\hline girl & devushka 3, devochka 2 & devushka 6 & saastaax 6 \\
\hline elderly & pozhilaja 2 & & ojdöx 2 \\
\hline smart & & umnaja 2 & 131 \\
\hline Total number & 161 & 144 & \\
\hline
\end{tabular}

In all the fields, we found specific responses that had no frequent correlates in other fields. The sum of such responses in RAF is 20 tokens, they are pregnancy / beremennost' (2), hair / volosy (2), children / deti (2), evil / zlo (2), beloved / ljubimaja (2), wise / mudraja (2), tenderness / nezhnost' (2), she / ona (2), bed / postel'(2), housewife / xozjajka (2). In UYAF the total sum of group-specific responses is 20: sex / seks (3), fat / tolstaja (3), woman (irrespectively) / baba (2), goddess / boginja (2), pride / gordost' (2), mystery / zagadka (2), affection, caress / laska (2), passion / strast' (2), bag / sumka (2). Rural Yakuts produced 48 distinctive answers: female person, lady / chüoche (11), male, man / $\jmath \dot{e} \dot{e} \jmath \dot{e}$ (5), old woman / éméexsin (5), a person with husband / kergénnèex kihi (4), mother of the family / yal ijète (4), elder sister, aunt / ejiij (3), a relative / ajmax (2), old / kyrjaghas (2), beautiful half / kèré ayar (2), has (with) children / ogholoox (2), weak / sylaabaj (2), boy / uol (2), clean, pure / yraas (2), young / èder (2). We must note that in the Russian group the number of tokens for any given group-specific response does not exceed 2. In UYAF it ranges from 2 to 3; for RYAF the quantities of such answers range from 2 to 11.

\section{Discussion}

To reveal the representations of 'woman' in the Russian and Yakut language consciousnesses, we classified frequent verbal reactions into thematic groups in order to compare the associative strategies and stereotypic reactions of the investigated subjects. The frequencies of the verbal responses were systematized into four thematic groups: Gender and Age Differentiation; Family Roles; Qualities, Characteristics, Emotions; Attributes.

\subsection{Gender and Age Differentiation}

RAF (70): man (55), human / person (8), girl (3), girl / female child (2), she (2). UYAF (62): man (45), girl (6), man / male (5), human / person (4), woman (irrespectively) (2). RYAF (94): man (33), girl (31), female / lady (11), human/ person (7), male / man (5), old woman (5), boy (2).

All the groups demonstrated an antonymic strategy of association, as the stimulus word 'woman' elicited answers denoting opposition by gender. 'Woman' was also associated with human / person by all the subjects. The English notion 'girl' has two equivalents in Russian 'devushka' and 'devochka' that differ in meaning: the first equivalent denotes, "1. a female person from adolescence to youth. 2. A person who has reached puberty, but has not yet married" [23]; the second "female child" [24]. As for the meaning of the Yakut notion 'girl' / 'kyys', it is wider than that in Russian; like in English it may refer to a child, adolescent or young woman. Thus, Russian respondents opposed 'woman' to not only young girl / devushka but female child / devochka; both responds represent synonymic notions of biological sex but with the differentiation in age. Rural Yakuts gave fewer responses of antonymic character 
(man) than other subjects did, but at the same time they produced more quantitative verbal reactions that specify a differentiation or opposition in age (girl, old woman). It is also necessary to note that we did not find the response old woman in other fields.

\subsection{Family Roles}

RAF (50): mother (30), wife (10), mummy (8), housewife (2). UYAF (43): mother (24), mummy (13), wife (6). RYAF (51): mother (33), wife (5), a person with husband (4), mother of the family (4), elder sister / aunt (3), a relative (2).

All the groups of subjects demonstrated the presence of the associative links 'woman' - mother, 'woman' wife. Therefore, we observe that 'woman' in both the Russian and Yakut language consciousness is associated with the image of mother and wife, meaning that the social role of a woman is strongly connected with family ties and domestic responsibilities, which for our respondents were more significant than other activities. Rural Yakuts, besides the reactions wife and mother, gave the responses elder sister / aunt and a relative that denote family members. Such answers (correlates) were not found in RAF and UYAF, even among singlefrequency responses. It is necessary to note that filiation is a relevant aspect for Turkic ethnic groups, for example, the same responses were produced by Khakass subjects whose associative fields, compared to the fields of the Russian Associative Thesaurus, contained verbal reactions referring to the theme 'relatives' / 'tuğanchağyn'. This specificity was found to be the main one that distinguished the psycholinguistic meaning 'woman' in the language consciousness of the Khakass due to their strong orientation to filiation [25].

\subsection{Qualities, Characteristics, Emotions}

RAF (46): beautiful (19), beauty (inanimate, means quality) (12), love (3), beauty (animate) (2), evil (2), beloved (2), tenderness (2), wise (2), elderly (2). UYAF (47): beauty (inanimate, means quality) (22), beautiful (6), fat (3), affection / caress (2), beautifully (2), goddess (2), love (2), mystery (2), passion (2), pride (2), smart (2). RYAF (28): beautiful / beauty (conversional notion) (7), elderly (6), beautiful (3), smart (2), old (2), beautiful half (2), weak (2), clean / pure (2), young (2).

All three groups demonstrated a predominantly positive strategy of association, as they produced mainly positive characteristics of 'woman', except for the answers evil, fat, and weak. These negative qualities refer to different themes: in RAF the response evil is connected with feelings and emotional characteristics of 'woman'; in UYAF fat represents a physical characteristic; in RYAF weak reflects either physical weakness or spiritual or emotional deficiencies stereotypically attributed to 'woman' in contrast to man. The stimulus word 'woman' also elicited verbal reactions reflecting strong stereotypic links between 'woman' and beautiful / beauty that specify the significance of qualities and characteristics connected with physical appearance. RAF and UYAF, unlike $\mathrm{RYAF}$, contained responses representing the importance of emotions and feelings (love, evil, beloved, tenderness, affection / caress, passion, pride). Russians and Rural Yakuts gave answers that specify intellectual qualities (smart, wise). As for the verbal reactions elderly in RAF, as well as old and young in UYAF, they are descriptions of 'woman' in terms of age characteristics. The response mystery is of metaphorical nature and can be explained by the existence of stereotypic idea that 'woman' is a mystery or riddle that a man should understand or solve. We think that the analogy 'woman is a mystery' reflects traditional sanctioned roles and functions that are assigned to men and women in the sphere of their relationships. Rural Yakuts also gave the answers clean / pure that represent the significance of either purity in soul or cleanliness and tidiness in domestic sphere [26]. Overall, we observe that Russians and Urban Yakuts gave more frequent responses characterizing physical attractiveness (beauty) as the main criterion of woman's estimation. This strategy of association reflects patriarchic representations and stereotypes about certain qualities attributed to a woman; the same strategy was noticed in the Russian and Khakass Associative Thesauruses where the prevailing number of woman's qualities was connected with physical appearance [27, 14].

\subsection{Attributes}

RAF (13): child (5), pregnancy (2), hair (2), children (2), bed (2). UYAF (12): child (7), sex (3), bag (2). RYAF (6): child (4), has (with) children (2).

All the groups of respondents produced answers representing ideas about maternity as a woman's main mission. Russian subjects and Urban Yakuts gave responses connected with the sexual sphere (bed, sex). In UYAF the verbal reaction bag represents either housewifely responsibilities (for example 'shopping bag') or material attributes of 'woman' (bag as an accessory). Overall, we see that this thematic group includes responses identifying stereotypic traditional female attributes and spheres.

\section{Conclusion}

The assignment of the verbal reactions to the four thematic categories allowed us to make the following general conclusion: the image of 'woman' reveals many commonalities between the three experimental groups, which can be explained by similarities in the perception of gender by the Russian and the Yakut people. The perception of 'woman' is stable as it is based on the preservation of traditional gender stereotypes of women's beauty and the family role in the process of describing or distinguishing their physical, internal and social aspects [25]. All associative fields include verbal reactions reflecting a patriarchal attitude to gender differentiation according to which a woman's social role is located within the family sphere that presupposes maternity and marriage. 
All groups of subjects produced an antonymic strategy of association by opposing woman to man and girl. In addition, respondents distinguished 'beauty' as woman's main attribute and, overall, presented a positive associative strategy. At the same time, some responses of Rural Yakuts were group-specific or quantitatively different when compared with other participants' answers. For example, in RYAF the number of reactions denoting 'Gender and Age Differentiation' is more than in the other associative fields, and Rural Yakuts gave the lowest number of verbal reactions related to the themes 'Qualities, Characteristics, Emotions' and 'Attributes'.

The comparison of frequencies produced by the investigated subjects revealed that there were more commonalities in associative fields of the Russians and Urban Yakuts than in those of the Urban and Rural Yakuts. We think that commonalities in the living environments and lifestyles of the Russian and Russianspeaking Yakut subjects greatly contribute to the divergence of Urban and Rural Yakuts' language consciousnesses. Cities in Yakutia are unifying spaces; within their infrastructures, Russian culture dominates over the traditional culture of the Yakuts. In such circumstances, the tendency by the Yakuts to use Russian on a broad scale in family interactions is prompted by the conscious intention on the part of a section of the Yakut population to obtain prestigious education and professions. Thus, cultural assimilation of minority ethnic groups is inevitable and leads to the transformation of their world image and convergence with the collective consciousness of the Russian people. As for the Yakuts from villages, i.e. agricultural regions of Yakutia, they lived in an environment where their native language dominated over Russian. Moreover, villages are characterized by relative stability in the sphere of gender roles due to underdevelopment of economic and social infrastructure as well as constancy in rural population and domestic surroundings.

It is necessary to conduct further research on the language consciousnesses of the Yakuts who were socialized in urban and rural environments. Such studies will contribute to the monitoring of the processes of assimilation of ethnic minorities with majority of the Russian culture.

\section{References}

1. A.P. Borgoyakova, The image of the world in the linguistic consciousness of the ethnos (Khakass. Russians. British) (Sovetskij pisatel', Moscow, 2003)

2. K. Graber, Lang. \& Commun 32 (2012) https://doi.org/10.1016/j.langcom.2011.05.005

3. K. Graber, J. Long, Inner Asia 11 (2009)

4. J. Little, J. of Rural St. 3 (1987) https://doi.org/10.1016/0743-0167(87)90052-0

5. J. Sumner, Sustainability and the civil commons: Rural communities in the age of globalisation (University of Toronto Press, Toronto, 2005) https://doi.org/10.3138/9781442684843
6. F. Dadvar-Khani, The J. of Rural and Com. Devel. 10, 63 (2015)

7. S. Filippova, E. Poarch, Eur. J. of Sc. and Theol. 16 (2020)

8. C. Arku, F.S. Arku, J. of Res. in Peace, Gend. and Devel. 1, 32 (2011)

9. M. Fine-Davis, Polit. Psych. 10 (1989)

10. D. Massey, Space, place and gender (University of Minnesota Press, Minnesota, 1994)

11. A.M. Blackstone, Human ecology: An encyclopedia of children, families, communities, and environments, 335 (ABC-CLIO, Santa Barbara, 2003)

12. A.M. Boudet, P. Petesch, C. Turk, M.A. Thumala, On norms and agency: Conversations about gender equality with women and men in 20 countries (The World Bank, 2013) https://doi.org/10.1596/978-0-8213-9862-3

13. N. Ellemers, Annual Rev. of Psych. 69 (2018) https://doi.org/10.1146/annurev-psych-122216011719

14. T.G. Borgoyakova, K.A. Pokoyakova, Vestnik NSU. Ser.: Ling. and Intercult. Com. 10 (2012)

15. I.E. Kalabikhina, Nauchnye Issledovanija Ėkonomicheskogo Fakul'teta 3 (2011)

16. E. Dalrymple-Alford, A. Aamiry, Psychonomic Sc. $21 \quad$ (1970) https://doi.org/10.3758/BF03335801

17. M. Debrenne, SHS Web Conf. 46 (2018) https://doi.org/10.1051/shsconf/20184605005

18. S. de Deyne, G. Storms, Behav. Res. Meth. 40 (2008) https://doi.org/10.3758/BRM.40.1.198

19. L. Istvan, I. Markovina, O. Endrody-Nagy, A. Makhmutova, J. of Psycholing. 39 (2019) DOI: 10.30982/2077-5911-2019-39-1-118-137

20. H. Kraievska, I. Gorofianiuk, L. Koval, E3S Web of Conferences 250 (2021)

21. M.I. Kysylbaikova, J. of Sib. Fed. Univ. Hum. and Soc. Sc. 15 (2021)

22. N.V. Ufimtseva, J. of Psycholing. 34 (2017)

23. S.I. Ozhegov, N. Yu. Shvedova, Tolkovyj slovar' Ozhegova [Ozhegov's Thesaurus]), entry 'devushka' (n.d.) Retrieved from: http://slovarozhegova.ru/word.php?wordid=6187

24. S.I. Ozhegov, N.Yu. Shvedova, Tolkovyj slovar' Ozhegova [Ozhegov's Thesaurus], entry 'devochka' (n.d.) Retrieved from: http://slovarozhegova.ru/word.php?wordid=6184

25. K. A. Pokoyakova, Ethnocultural and gender aspects of the representation of the binary opposition man / woman in the language consciousness of the speakers of the Khakass, Russian and English languages (Archive of Electronic Resources of Siberian Federal University, Krasnoyarsk, 2016) Retrieved from: http://elib.sfu-kras.ru/handle/2311/141082 
26. Yakut Online Dictionary, entry 'yraas' (n.d.) Retrieved from: https://sakhatyla.ru/translate?q=ыраac

27. N.V. Ufimtseva, Ethnocultural specificity of language consciousness (Az buka, Barnaul, 1996) 